\title{
Sven Spieker: el archivo en pleno juego
}

\author{
Sven Spieker: Archive in Full Force \\ Sven Spieker: o arquivo em pleno jogo
}

\section{Camila Pulgar Machado}

UNIVERSIDAD CENTRAL DE VENEZUELA, CARACAS, VENEZUELA

Profesora de la Escuela de Letras de la Universidad Central de Venezuela.

Magíster en Estudios Literarios en la misma Universidad. Obtuvo

la beca Fulbright (2013-2014), con la cual desarrolló su investigación

doctoral en el Departamento de Literatura y Lenguas Hispánicas de

la Universidad de Pittsburgh. Ha publicado los libros La materia y

el individuo. Estudio literario de Sociedades Americanas de Simón

Rodríguez (El perro y la rana, 2006), Miguel Otero Silva (El perro y la rana, 2006), y los ensayos de introducción de Sujeto al límite: ensayos de cultura literaria y visual de Julio Ramos (Monte Ávila, 2012) y de la edición venezolana de Desencuentros de la modernidad en América Latina. Literatura y política en el siglo XIX de Julio Ramos (El perro y la rana, 2009). Correo electrónico: camilapulgarmachado@gmail.com

\section{Artículo de reflexión}

Documento accesible en línea desde la siguiente dirección: http://revistas.javeriana.edu.co

Este ensayo académico comprende originalmente cuatro apartados. Por motivos de espacio, aquí solo expongo el I y el IV, y dejo por fuera los que estuvieron dedicados al principio de procedencia (II) y a Freud, Duchamp y Breton (III). Agradezco a Juan Cristóbal Castro, pues gracias a su iniciativa tuvimos a Sven Spieker en Caracas. Agradezco su apoyo intelectual, en todo momento, en lo concerniente al tema del archivo. 


\section{Resumen}

Este ensayo analiza la teoría del archivo de Sven Spieker y su a priori histórico, que es determinado por la noción de juego y la instalación de arte finisecular. El estudio esclarece cuál es el punto de vista del autor en su complejo libro The Big Archive; perspectiva diacrónica que parte de un análisis contemporáneo del archivo arqueológico fundado en Alemania en 1881 y que se extiende hasta un arte del anti-archivo pero de impulso archivístico, como el de Duchamp, y otras indagatorias que acontecen en el Surrealismo, las galerías del Constructivismo ruso, el arte de instalación, etc.

Palabras clave: teoría de archivo; principio de procedencia; espectro lúdico; impulso archivístico; museo-archivo; visitante activo; archivo

\section{Abstract}

This essay analyzes Sven Spieker's theory of archives and its historical a priori, as determined by the notion of game and the installation of end-of-thecentury art. This study clarifies what is the point of view of the author in his complex book The Big Archive. A diachronic perspective starting with a contemporary analysis of the archaeological archive founded in Germany in 1881, and that extends up to the anti-archive art, based on an archival impulse, such as that of Duchamp, and other inquests that occur in Surrealism, the galleries of Russian constructivism, installation art, etc.

Keywords: archive theory; origin principle; ludic spectrum; archival impulse; museumarchive; active visitor; archive

\section{Resumo}

Esta comunicação analisa a teoria do arquivo de Sven Spieker e o seu a priori histórico, determinado pela noção de jogo e a instalação da arte finisecular. O estudo esclarece qual o ponto de vista do autor no complexo livro The Big Archive; perspectiva diacrónica que parte de uma análise contemporânea do arquivo arqueológico fundado na Alemanha em 1881 e que se estende até uma arte do antiarquivo ainda que de impulso arquivístico, como o de Duchamp, e outras investigações que acontecem no Surrealismo, as galerias do Construtivismo russo, a arte de instalação, etc.

\section{Palavras-chave: teoria}

de arquivo; princípio de procedência; espectro lúdico; impulso arquivístico; museuarquivo; visitante ativo; arquivo

\section{Cómo citar este artículo:}

Pulgar Machado, Camila. "Sven Spieker: el archivo en pleno juego". Cuadernos de Literatura 21.41 (2017): 30-48. https://doi.org/10.11144/Javeriana.cl21-41.ssap 


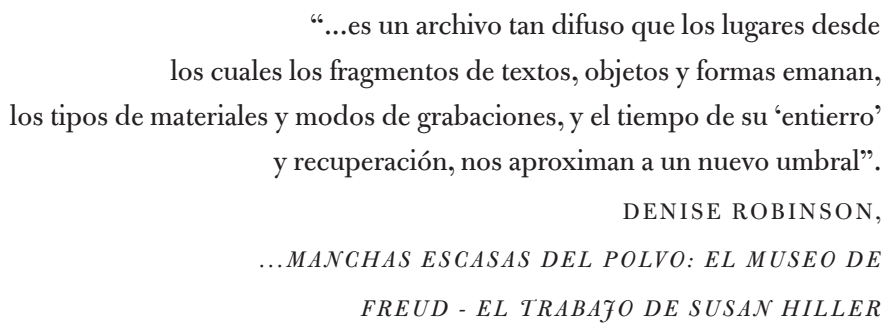

I

El Li B Ro EL gran archivo. El arte desde la burocracia (2008), del crítico alemán Sven Spieker, contiene una historia del archivo que ha sido construida por medio de la lectura del principio de procedencia, que el autor identifica con una fecha y un lugar. En la primera línea del segundo capítulo, Spieker puntualiza: "Quiero comenzar con una fecha y un lugar. En 1881, el llamado Provenienzprinzip o principio de procedencia (PP) fue introducido en el Archivo Estatal Privado de Berlín" (Spieker). ${ }^{1}$ Sin embargo, se advierte que la interpretación de esta directriz (PP), gestora del archivo decimonónico, está sujeta a su crítica o a una puesta en tela de juicio de largo aliento. A continuación, el libro despliega una secuencia de situaciones desarticulantes de esta instancia arqueológica fundamental en la percepción del archivo afirmativo que, por su parte, enfatiza el origen topológico, la legibilidad de los documentos y el registro del tiempo contingente; del tiempo vital al que remiten sus hallazgos (Id. 132). No se trata, como Spieker también esclarece en los preámbulos de su disertación, siempre atenida al estudio de la historia y sus condiciones específicas de producción, ${ }^{2}$ de una entelequia metafísica.

El subtítulo del segundo capítulo, dedicado exclusivamente al análisis minucioso del principio de procedencia, nos ubica "después de Hegel" (Id. 17). Spieker explica que tanto científicos como historiadores inspirados por esta lógica arqueológica, como el mismo Walter Benjamin, fueron objeto de la seducción de la materialidad concreta del lugar en donde los documentos fueron generados. Dicha comprensión se opone a la anterior interpretación del conocimiento; evaluación kantiana que expresamente elevaba su producción intelectual a ámbitos en donde el anhelo de realización física o material era rechazado.

\footnotetext{
1 Todas las traducciones del inglés al español son mías.

2 Se emplea la jerga que Michel Foucault utiliza en La arqueología del saber (1970).
} 


\section{Polos}

De inmediato, en realidad desde la Introducción, el primer capítulo o incluso antes, desde una suerte de pródromo titulado "Dieciséis cuerdas", Spieker se ubica en "el uso de archivos que hace el arte del tardío siglo XX" (Spieker 1). El autor sostiene que este "reacciona de formas diversas" (Ibid.) a las rupturas que las vanguardias, a comienzos del siglo XX, operaron en "la objetivación (y fetichización) del tiempo lineal y del proceso histórico decimonónicos" (Ibid.). De ese modo, el análisis que propone El gran archivo tiene como punto de partida el arte de finales del siglo XX que realizaron artistas como Ilya Kabakov, autor de la instalación "Dieciséis cuerdas" y artífice de otra instalación cuyo título fue, precisamente, "El gran archivo".

Colocando ese asunto allí, en el background, en el trasfondo de su disertación, Spieker se desplaza hacia su lectura del principio de procedencia, para culminar con el análisis de Marcel Duchamp o de la primera gran reacción artística contra la crisis del almacenamiento; elaboración "basada en un embotellamiento gigante de papel", en "el aumento exponencial de los datos almacenados" (Id. 5) por la actividad creciente de la administración pública hasta el umbral que se sitúa a principios del sigo XX.Entonces, Spieker introduce la noción, fundamental en su libro, de un arte del anti-archivo que funcionará mediante "intervenciones críticas al archivo del siglo XIX y su ambición de reconciliar la contingencia del tiempo con la continuidad simbólica de la representación" (Id. 51).

Partiendo de esa base contradictoria, propia de las vanguardias tempranas que Spieker analiza en un artista como Duchamp; es decir, de la noción de un arte del anti-archivo que es un primer gran deconstructor de la concepción arqueológica del archivo del XIX, el autor entra en el análisis del arte tardío del siglo XX de pulsión archivística. El crítico alemán desarrolla su exégesis como si para poder comprender, desde 1970 hasta el 2000, las producciones de artistas como Hans-Peter Feldmann, Susan Hiller, Gerhard Richter, Walid Raad y Boris Mikhailov, tuviera que mirarse o, de modo aun más decisivo, tuviera que construirse necesariamente una perspectiva de la historia como aquella en la que él inscribe su reflexión.

De tal modo, antes de iniciar la lectura que propongo de este libro, quiero subrayar esas dos tendencias historiográficamente delimitadas en El gran archivo, generalizándolas con la intención de mostrar los polos más claros y dominantes del argumento central. Finalmente El gran archivo es un libro ordenado cuya estilística está fundada en la nitidez.

En los dos últimos capítulos del libro, "1970-2000, archivo, base de datos y fotografía" y "El archivo en juego", Spieker puntualiza esta dualidad. Primero, se formula una manifestación artística y conceptual dominada por la búsqueda de la 
"procedencia singular" (Id. 134), es decir: la procedencia no comparable - pero, sobre todo, no sustituible - del documento; su origen único, que produce, cuando se lo investiga, una secuencia cronológica: un ordenamiento de los planos del documento mediante el que se accederá al misterio de ese otro lugar en donde, a su vez, los usuarios del archivo podrán constatar el tiempo-espacio del nacimiento de la evidencia que ha guiado el viaje hasta esa dimensión perdida de la historia. Tal es la aspiración arqueológica, herencia del archivo científico del siglo XIX.

$\mathrm{Y}$, segundo, prevalece un arte opuesto, contradictor de este principio de procedencia pero provisto de una actitud también archivística. Así lo sostiene Spieker cuando aborda el arte de Marcel Duchamp, "cuya actitud hacia su propio trabajo fue archivística de muchas maneras" (Ibid.). En los readymades y stoppages "se registra el tiempo no como una continuidad sino en la forma accidental de las fisuras y las cicatrices sobre una superficie que de otra manera estaría regulada" (Id. 54). Más adelante, ya cuando las características de esta tendencia están expresándose en diversas apuestas artísticas que Spieker aborda, vemos cómo el fotomontaje desautoriza al principio de procedencia, atacándolo directamente mediante el énfasis del shock, de la ruptura y de la proliferación de las bases o los planos del archivo (Id. 132).

\section{Punto de vista}

Quiero marcar dos momentos del libro en los que el autor precisa su punto de vista. He optado por empezar por el final: el último capítulo o ensayo - siempre hay esta dualidad, un capítulo de El gran archivo es un ensayo en sí mismotitulado "El archivo en juego". Spieker apunta:

En este capítulo me enfocaré en un curador y tres artistas contemporáneos - Michael Fehr, Andrea Fraser, Susan Hiller, Sophie Calle - quienes han variadamente cuestionado la lógica arqueológica del archivo introduciendo error, inscripciones falsas y fantasmáticas, objetos robados, herramientas de búsquedas ficticias dentro de sus operaciones; revelando, en el mecanismo que los archivos desencadenan, aquello que distingue la historia de la ficción, los datos falsos de los auténticos, los objetos verdaderos de sus supuestos homólogos pero ilegítimos. El mínimo común denominador de estos procedimientos es la noción de juego... En el ensayo temprano titulado "La estructura, el signo y el juego en el discurso de las ciencias humanas" (1966), Derrida propuso dos maneras de pensar el juego. La primera forma incluye un centro estable o terreno que permite el juego pero permanece ella misma exenta de sus efectos ("una inmovilidad fundamental y una certeza tranquilizadora"); mientras la segunda carece de esa base estable y no está autorizada ni en la historia ni en la hermenéutica. (Id. 174, énfasis de la autora) 
Así, Spieker ofrece, en primer lugar, una aproximación al archivo que juega o se juega en el quiebre de sus presupuestos decimonónicos, des-objetivando o desmontando sus premisas básicas. De acuerdo con este punto de vista, hasta cierto momento postmoderno, el archivo o, mejor, la pulsión y la voluntad archivísticas que Spieker privilegia, implican un inquietante doble cuestionamiento: en primer lugar, se pone en tela de juicio, se revisa y contrasta la noción de archivo que operó en Alemania a partir del año 1881, y que según se lee en El gran archivo, influyó tanto en los modelos de Freud - su dibujo del aparato psíquico - como en los de Walter Benjamin — su devoción por el oscuro lugar del acontecimiento que trae el recuerdo-. Y, en segunda instancia, prevalece una emocionante puesta en tela de juicio de la noción arqueológica foucaultiana; concepto que continúa un aspecto fundamental de esa concepción decimonónica alemana que tuvo su expresión en Francia asimismo, pero que, con Foucault, ahora se basa particularmente en el recorte de los hechos asumidos como cuadros del discurso - y no, como en el siglo XIX, como lógica de las evidencias y de los acontecimientos 'puros' de la historia-.

En un paréntesis, Spieker elucida este vínculo entre ambas nociones de archivo: (No coincidentemente, Derrida también une la arqueología - cercana prima del archivo decimonónico - al primer tipo de juego, explicando que "uno tal vez pueda decir que el primer movimiento de toda arqueología, como el de toda escatología... es siempre un intento por concebir la estructura sobre la base de una presencia plena que está más allá del juego".) (Spieker 175) ${ }^{3}$

A primera vista infiero que Spieker está en 'el juego', nunca detrás de una 'presencia plena', cuando inquiere sobre ese archivo en singular: el gran archivo que, no obstante, le da título a su libro. De acuerdo con el magistral texto de Derrida Mal de archivo. Una impresión feudiana (1994), podría sugerir que el asunto acá es justamente el pleno juego del Archivo. Cuando Spieker lo mira, este entra en pleno al juego, o se juega allí, antes o después de las conclusiones de esos grandes universales supuestamente unívocos e inmunes a los estragos de las excavaciones y de los experimentos intervencionistas; a salvo siempre de la inteligencia lúdica y de su acumulación o tráfago de significantes. También diría que, a pesar de estar ordenados cronológicamente, los planteamientos del libro apuntan con certeza hacia el porvenir y "los dispositivos", "los ritmos de lo que confusamente se llama la «comunicación»" (Derrida 2). En ese contexto, Spieker no se plantearía, como Derrida, la pregunta por el psicoanálisis —“ ¿Qué porvenir tiene el psicoanálisis en la era del correo electróni-

3 Los cuadros del discurso, nomenclatura de La arqueología del saber. 
co, de las tarjetas telefónicas, de los multimedia y del CDrom?" (Ibid.)-, sino que, estimulado por lo que Hal Foster ha llamado impulso archivístico o pulsión archivística (Foster), centraría su atención en la inquietud por el imaginario contemporáneo; preocupación que corresponde a un grupo diverso e indefinido de artistas. De ese modo, la opción de Spieker se desliza hacia la lúdica flexibilización perenne de las condiciones de almacenamiento y sus representaciones artísticas.

Entonces, marco el segundo momento en el que el autor precisa su punto de vista. Y me atrevo a utilizar una cita extensa, puesto que la necesitamos en español. Vale la pena anotar que esta lectura busca también poner a Spieker en español. Veamos:

La visión modernista se identifica frecuentemente con una mirada que no archiva, ideal y vacía, que no conoce ni objetos ni sujetos, descrita por Foucault como "la ingenuidad brillante, distante y abierta de la mirada". Evaluar el ataque de las vanguardias a este tipo de autonomía no archivística que, según Krauss, alcanzó su cima en el impresionismo y el neoimpresionismo, es confrontar un modelo de mirar para el cual el archivo es relevante no como una cuadrícula vacía e ideal esperando que se la llene con objetos sino como un lugar al cual los objetos regresan ya fabricados. En esta lectura la pureza libre de la modernidad, su devoción por el origen como una salida absoluta, el famoso "sin borrones" (la mirada límpida), puede funcionar solo hasta el punto de que nosotros marginemos el archivo en que está fundada. (Ibid.)

La advertencia nos deslinda, aunque no totalmente, de alguna identificación con las supuestas presencias plenas de la lógica occidental que deconstruye Derrida en su Gramatología, y nos obliga como lectores a poner en tela de juicio el título del libro. Ese gran archivo está siendo visto - porque Spieker es un ojo, una perspectiva visual sobre los espacios físicos, los cuerpos de archivos, como no lo son ni Foucault ni Derrida - y analizado por una subjetividad radicalizada, que opera constantemente presionando grandes argumentos.

\section{Lectores}

De tal manera, puedo sugerir que en términos generales El gran archivo alimenta con sus despliegues a dos tipos de lectores. Esto lo observo dado que me diferencio del lector avocado plenamente a la crítica de arte, a los espacios como el museo y a la galería, en donde Spieker proyecta su ideario. Es decir, el libro se abre, por una parte, hacia el crítico de arte y el artista lector con la inquietud por los espacios gramatológicos y visuales del archivo. Por otra parte, me incluyo entre los lectores investigadores académicos que, muy especialmente, luego de $L a$ 
arqueología del saber de Foucault, y, en segunda instancia, de Mal de archivo de Derrida, buscan una re-interpretación cultural del tópico que pueda esclarecer, con la exigencia que ello implica, los asuntos de la actualidad y, por consiguiente, de la operatividad digital, instrumental de los archivos en el siglo XXI.

El gran archivo construye así una imagen de la historicidad del tópico que es vista a través de cada capítulo: un episodio marca un caso de archivo que se extiende desde 1881 hasta el presente, a pesar de que el propio autor evite llamarse a sí mismo historiador. No obstante, la perspectiva diacrónica es estructurante. Si bien varios capítulos del libro pueden leerse por separado, en calidad de ensayos realmente estimulantes sobre la situación del archivo en la escena del arte contemporáneo, El gran archivo contiene un argumento que representa una de sus mayores riquezas y que recorre al libro en su organicidad. Dicho argumento es la fuente a la que recurrimos los lectores inquietos por la futuridad, tan próxima al presente, de los micro archivos donde trabajamos; pero - y considero que esta advertencia es fundamental - no en relación únicamente con la acumulación, el deslinde y la exposición al público de unos datos reinterpretados, que sería el aspecto técnico o mecánico del trabajo en archivos. Los lectores que valoramos la fuerza argumental de la propuesta de Spieker, y que no partimos necesariamente de la mirada artística, trabajamos asimismo pensando en los acontecimientos epistemológicos generados por la dimensión del archivo — estando allí, dentro-: un sitio particularmente afectado por el tránsito histórico, el azar, y por las transformaciones comunicacionales.

En suma, los acontecimientos de este investigador tipo con el que por lo pronto me identifico, se accidentan en los intersticios de los archivos y deben ser sostenidos por el hilo de una lucidez que tiene que hacerse a sí misma en la capacidad de contemporaneizar, es decir: de intervenir de alguna manera estas cargas documentales de pasado.

Spieker responde a la pregunta ¿qué es el archivo? Y desde allí, para algunos, responde a más de un asunto relativo a la investigación. Su respuesta nunca es una sentencia concluyente. No hay manera de cerrar la apertura del juego, gramatológicamente hablando, ni de subsanar el horror vacui de aquel entregado a esta híper conciencia que produce toda noción de archivo. Un archivo nunca es una pequeñez. 
IV

Una de las primeras menciones a Michel Foucault en El gran archivo, nos dirige de inmediato a los últimos capítulos del libro, que se constituyen, en definitiva, como la teoría del archivo de Sven Spieker. En ambos capítulos, el crítico alemán aborda apuestas artísticas en las que se dan distintas tendencias que parecen más bien una misma actitud: la disidencia de los artistas a la trascendencia o transparencia del significado contenido en archivo. Foucault emerge entre estos artistas, pues si bien su pensamiento advierte la existencia del archivo, nunca lo admite como una instancia clara, definida. Por el contrario, el asunto yace en el reconocimiento de la dispersión. Paradójicamente, allí, en ese lugar, en trasfiguración perenne y en los intersticios de nuestra miscelánea, se "establece — en palabras de Foucault- que somos diferencia, que nuestra razón es la diferencia de los discursos, nuestra historia la diferencia de los tiempos, nuestro yo la diferencia de las máscaras. Que la diferencia, lejos de ser origen olvidado y recubierto, es esa dispersión que somos y que hacemos" (Foucault 223). En esta dispersión opera el archivo y su irónica positividad, o el a priori histórico que, según Spieker, puede palparse, más o menos, en las obras de estos post-vanguardistas constructores de la imagen del gran archivo; figuración que, sin embargo, "no se impone desde el exterior sino [que] emerge del archivo mismo" (Spieker 12). Foucault concluye que "la positividad de un discurso" es "el espacio limitado de su comunicación" (Foucault 214). Así Spieker mira estos archivos atrapados en las mismas cosas que ellos conectan (Spieker 12).

\section{Rebelión del significante y espectro lúdico}

Por una parte, en el séptimo capítulo de su libro, "1970-2000, archivo, base de datos y fotografía", Spieker estudia a Hans-Peter Feldmann (Alemania, 1941), Susan Hiller (USA, 1940), Gerhard Richter (Alemania, 1932), Walid Raad (Líbano, 1967) y Boris Mikhailov (Ucrania, 1937), quienes producen sus obras a partir de la proliferación de significantes (fotos e intervenciones escritas) rebeldes a una significación monumental o mítica.

Spieker apela a la noción de mito que ofrece Roland Barthes y que implica que el tráfago de significantes es una dimensión secundaria, perteneciente a un sistema semiológico lingüístico que materializa la esencia del otro sistema semiológico primario en donde yace la dimensión o exigencia mítica. Este último es el metalenguaje, al que alude el lenguaje-objeto o el significante. Así "el semiólogo, no necesita" exagerar "la pregunta que se hace sobre la composición del lenguajeobjeto", "él solo necesitará conocer el término total, el signo global" (Id. 212), y preguntará a los significantes en la medida en que estos contribuyan al mito. 
Concluimos que este grupo de artistas de la fotografía mantiene marginado el nivel mítico, que es completamente relativizado. A esta trascendencia monumental se le mira en falta, en su ausencia y, desde esa radicalización del juego, se palpan las diferentes texturas, voces, miradas, materias y sentidos del vacío que conforman ese "campo en el que pueden eventualmente desplegarse identidades formales, continuidades temáticas, traslaciones de conceptos, juegos polémicos" (Id. 215).

Por otra parte, el espectro lúdico del espacio archivístico domina, desde cierta tensión estética, el octavo y último capítulo, "El archivo en juego", desapareciendo de su condición lo que Spieker llama la "inmunidad del archivo a la manipulación" (Id. 175). Los espectadores de este arte de instalación, principalmente, son inducidos a convertirse en agentes parecidos al espectador emancipado que Jacques Rancière describe. Por ello, "la base de esta interacción" entre el público y el espacio abierto, que se dirige hacia la alteración de las "premisas básicas", "incluyendo el principio de proveniencia", "es una forma de juego que abandona lo que es tal vez la más fundamental suposición del archivo moderno, la suposición de que el archivo funciona como un tipo de orden analógico-tecnológico de la memoria" (Ibid.). Así, lo que acá llamo el archivo en juego implica un arte fenomenológico que puede desencadenar una gran turbación, en contraste con la vigilancia lógica del sentido ulterior de un archivo lógico que había prevalecido controlando estos lugares.

Aquellos sitios están siempre imantados, dados sus comportamientos inconscientes: la acumulación de sentido y la producción de deshechos. En este capítulo, Spieker trabaja las propuestas de un curador y tres artistas contemporáneos: Michael Fehr, Andrea Fraser, Susan Hiller y Sophie Calle. Veamos un extracto:

Una de las más escandalosas instancias de interferencia en el archivo es la alteración voluntaria de sus documentos, los actos de destrucción, o de eliminación de registros. Tal es la estrategia perseguida por Andrea Fraser, quien recibe a los visitantes de la sala de información en el Museo Bern Kunsthalle para rumiar con ellos sus documentos al punto de un completo desorden. En cambio, Susan Hiller y Sophie Calle siguen el procedimiento contrario. En sus trabajos, el hecho de dejar una huella no es producto de la remoción o la destrucción voluntaria de un objeto. En lugar de esto, ambas artistas crean para-archivos o archivos paralelos que se yuxtaponen al archivo y su ambición de registrar la contingencia, creando una serie de suplementos que cuestionan los basamentos de la hermenéutica del archivo. (Ibid.) 


\section{Archivo-museo y visitante activo}

Indudablemente, esta espacialidad especulativa del archivo se ha ido tomando el museo. Aquello constituye un motivo de El gran archivo. Desde el capítulo sexto, "Alrededor de 1925, el cuerpo en el museo", Spieker nos mantiene como lectoresespectadores adentro de salas, galerías laberínticas y espacios museísticos vivientes. De hecho, esta es la discusión con la que emprende este maravilloso capítulo sobre El Lissitzky y Sergei Eisenstein. En ese sentido, yo agregaría a Aleksandr Rodchenko, quien no está referido en el subtítulo del capítulo, pero que Spieker trabaja a partir del surgimiento de una cierta rivalidad que lo opuso a Lissitzky - cuando Rodchenko era el jefe del Buró del Museo Soviético- hasta la aparición de su obra archivística Monumento a Lenin, a 4 años de la muerte del líder comunista.

Por una parte, Lissitzky construye las galerías o salas del Constructivismo Soviético, que se articulan a partir de un cambio radical en el tratamiento de la percepción. Estos espacios futuristas se fundamentan en una "dinámica óptica" que exige la "activación del visitante", ahora "agente activo" (Id. 110) y base principal del archivo contenido potencialmente en el espacio observado. Apunta Spieker: "Solo hay un archivo, el de las percepciones del visitante" (Id. 125) que, al transitar con su cuerpo en el museo, crea la oscilación necesaria para que se geste y acontezca lo que la sala muestra en medio de sus paredes portátiles y sus imágenes temporales: las salas constructivistas no se detienen más en la "autonomía estacionaria del punto de vista correcto (Ranke)" (Id. 109). En tales términos, el autor aborda la problemática de la mirada correcta, que defendía el historiador alemán Ranke en el siglo XIX y desde donde se apreció el fenómeno arqueológico orgánico al archivo del principio de procedencia.

Sometiendo el museo - tradicionalmente basado en un entendimiento newtoniano del espacio como un recipiente homogéneo para objetosa un proceso de diferenciación continua, las Salas de Demostración se enfocaron no tanto en la autonomía del espacio arquitectónico como en su observador humano. (Id. 108)

El planteamiento de Spieker consiste en que, si bien estas salas o galerías diseñadas por la conceptualización de Lissitzky ambicionaban la presentación del arte contemporáneo en una escena libre de desorden y hacinamiento, "su misión económica" (Ibid.) estaba vinculada, sin embargo, "a un giro en los parámetros archivísticos de ver y en la restructuración del museo defendida por Stepanova" (Ibid.); otra ideóloga de este campo cultural, que trabajaba directamente para el proyecto estatal de Rodchenko. Es decir, el fenómeno de 
salas de arte descargadas de objetos no contradecía la vocación archivística que inspiró a Lissitzky en su proyecto político.

Sobre este campo intelectual soviético y sus vertientes, leemos en $E l$ gran archivo:

Stepanova escribió que "el valor 'sagrado' del trabajo artístico como el único tipo de originalidad se ha desvanecido. El Museo como un repositorio de esta originalidad está siendo transformado en un archivo". Citado en el influyente libro El experimento ruso en el arte, 1863-1922 de Camilla Gray, este pasaje ha sido interpretado como la consignación final del arte de museo "a los archivos" o, por el contrario, como una aprobación de su transformación en un archivo - el archivo como el "nuevo museo"- . Dado que Stepanova defiende aquí no la eliminación del museo sino meramente un cambio en el modo en que este funciona (no más como un repositorio de la originalidad sino como un archivo), la segunda lectura parece ser más plausible. Sin embargo, una tercera variante es también posible, en la cual no sería un problema la disolución del viejo museo en el archivo, ni tampoco su desaparición simple, en todo caso la incorporación del archivo en el museo, desencadenando una interacción dinámica entre la representación y el tiempo contingente, entre la muestra estática que caracteriza el museo de arte tradicional y una más activa forma de recepción. Yo argumentaría que dicho archivo-museo viene a estar cerca de lo que Rodchenko definió como el nuevo museo de "cosas vivientes" - un museo devoto al "origen dinámico que conduce al arte hacia delante" - y estas ideas relacionadas también inspiraron los diseños de la galería innovadora... que Lissitzky construyó en la mitad de 1920: la Sala para el Constructivismo... en Dresden, que exhibió trabajos de Mondrian, Léger, Picabia, Moholy-Nagy, Naum Gabo, y Lissitzky, y el Gabinete de lo Abstracto... (1927-1928) en el Museo de la provincia de Hannover. (Id. 108)

De tal forma, a partir de este capítulo, que gira en torno a la innovadora apreciación archivística soviética — el museo de cosas vivientes, por un lado, y el perspectivismo perceptual del espectador (el cuerpo en el museo), por el otro-, Spieker desemboca en la lectura de La historia de la clínica de Foucault. A continuación, el crítico alemán señala la observación de Foucault de cómo la escritura en la práctica médica emergió como construcción y control de un nuevo orden discursivo, que silenció "la inmediatez de la mirada sin restricciones". "La escritura intervino para concentrar el conocimiento en las manos de unos pocos" (Id. 114). Antes de este momento - agrega Foulcault - en que se creó un corpus de 
conocimientos escritos (un saber), existía la relación inmediata y universal de la humanidad consigo misma. De hecho, considero que esta referencia que hace Spieker a la lectura foucaultiana del archivo tiene más de una dirección en su libro.

En principio, Spieker formula su análisis del perspectivismo de Lissitzky y de cómo este creador ruso pudo ir más allá de la visión, tal como fue entendida en el siglo XIX. Primero partió de lo establecido por los mismos experimentadores del siglo XIX, $\mathrm{y}$

al confrontar al espectador (visitante) con dos superficies independientes y aún relacionadas o relacionables - la armadura en las paredes y las imágenes colgando en estas-, la sala de demostración asimila la lección principal enseñada por la fisiología óptica del siglo XIX: la noción de que la visión no es instantánea sino un constructo que recibe información de las diferencias y los intervalos. (Ibid.)

En consecuencia, partiendo de la visión binocular Lissitzky no va a impedir el reconocimiento y menos la aceptación de la disparidad (la disparidad de vistas distintas) para favorecer, como hizo el espíritu ordenador del XIX, la ilusoria apreciación del movimiento unitario. Así,

el modelo de visión implícita en este cambio entraña la permanente oscilación entre el trasfondo archívistico y su superficie, una oscilación que impide una distinción confiable entre los dos elementos, que es como tal el prerrequisito para la integración del tiempo y el espacio en las Salas de Demostración (Id. 115).

Es decir, no hay certeza sólida.

Comprendemos cómo, a partir de este constructivismo se replantea el asunto de la visión, que adquiere nuevamente la posibilidad de lo directo y sus oscilaciones (no más corregidas) como formas plenas de conocimientos o experiencias cognoscentes. De tal manera, al cierre de este sexto capítulo, Spieker puntualiza qué sería entonces un "sistema experimental":

En los términos del laberinto de Rheinberger, tocar, tantear táctilmente, significa no permitir que lo que nosotros ya sabemos o ya hemos aprendido, interfiera con nuestra precepción de lo nuevo. Estar presente en lo nuevo es encontrar que el viejo modelo epistemológico basado en el archivo de conocimientos que trasciende la experiencia y la presencia corporal, está obsoleto.(Id. 128) 


\section{Una teoría del archivo después de Foucault}

De tal modo, a estas alturas del libro, Spieker le da una respuesta a aquella pregunta que se hiciera al comienzo, en su Introducción, sobre el artista estadounidense Robert Morris y su obra Fichero (1962):

¿Continúan Morris y el arte del tardío siglo XX en general el cuestionamiento del archivo de las palabras que Foucault ve como centro de gravedad del siglo XIX? (Id. 13, énfasis de la autora)

Sin duda, este centro neurálgico de un archivo cuyos fundamentos son discursivos y limitados por órdenes de control disciplinarios, trasciende al siglo XIX y forma parte de la misma comprensión que Foucault tenía del asunto en La arqueología del saber. De hecho, considero fundamental tocar en este amplio comentario en torno a El gran archivo, la diferencia fundamental que hay entre Spieker y Foucault. En primera medida, debe anotarse que Spieker lo trae a escena (en más de una oportunidad) para entablar un vínculo con la esencia misma del archivo, que estaría situada en la entropía o en la dispersión; en lo siniestro o en la disrupción que se plantea al margen de esos mecanismos ordenadores inmanentes a las disciplinas o saberes, pero en donde hay siempre algún tipo de producción que deslumbra. Es decir, como Allan Sekula, además de localizar los mecanismos de represión del gran archivo "del sueño moderno del control total de la abarcadora disciplina administrativa" (Id. 1) — "gigante archivo en el centro de una realidad fundada en la racionalidad ordenada" (Ibid.) - , Foucault comprende que allí mismo hay otro archivo, justamente el que él describirá: "su lugar [agrega Foucault] es el margen de nuestras propias prácticas discursivas" (Foucault 222). Desde allí, también, Sekula se pregunta por la práctica modernista autorreflexiva del arte.

Foucault explica que el término de arqueología que él acuña en su método dista de actuar excavando el origen de lo perdido:

Este término no incita a la búsqueda de ningún comienzo; no emparenta el análisis con ninguna excavación o sondeo geológico. Designa el tema general de una descripción [discursiva] que interroga lo ya dicho a nivel de su existencia... La arqueología describe los discursos como prácticas especificadas en el elemento del archivo. (Id. 223)

En términos de Foucault, ese elemento "nos desune de nuestras continuidades: disipa esa identidad en que nos gusta contemplarnos a nosotros mismos para conjurar las rupturas de la historia[,] ... hace que se manifieste el otro y el exterior" (Id. 223). La interrupción que ve Foucault, y que constituye el archivo propiamente 
dicho, se acumula como rareza gracias a sus iteraciones, repeticiones y arbitrariedades intrínsecas. Es decir, este evento disruptivo, que constituye asimismo el punto de partida de Sven Spieker, acontece en campos magnéticos de acción discursiva en donde se plantea un corpus (un saber). Se genera, entonces, un desorden que observar y describir. Sin embargo, la percepción de Foucault se originó en su relación con dichos temas generales disciplinarios, o sea discursivos y aún inmunes a las erosiones de la dimensión cibernética. Dicha dimensión corresponde en este caso al actual tejido comunicacional de la contemporaneidad; justamente el que produce ese elemento entrópico, planteándose un hiper-significante: un nuevo tipo de materialización cognitiva capaz de desconocer, sin pena ni gloria, la totalidad de las instancias monumentales en contra de las que Foucault escribió su teoría pero que le fueron entrañables en su planteamiento.

En todo caso, y evitando extremismos, la 'desaparición' de los sistemas generales de los que depende la búsqueda de archivo del arqueólogo foucaultiano, es intermitente. Se prende y apaga con las fluctuaciones de una dimensión comunicacional inédita, aún para la fecha de publicación de $L a$ arqueología del saber. Hay más de una textura hoy en día planteada en espacios y con medios que Foucault no tuvo a la vista; cosas antes que palabras que irrumpen en umbrales no necesariamente epistémicos y que siguen construyendo, manifestando, una productividad de pulsión archivística. Ya no se trata estrictamente del a priori histórico versus los formales, que son los carentes de contingencia, aquellos que se les percibe inmunes a los efectos erosivos de los archivos aledaños; porque ahora el asunto no siempre entraña ni corresponde con el saber disciplinario y sus dispersiones o transformaciones: el archivo puede carecer de comunicabilidad. Lo principal tampoco es una acumulación críptica establecida en relación con la vigilancia y el control. En conclusión, hoy hay una práctica indiferentemente rebelde que articulan con manifiesta arbitrariedad los artistas-fotógrafos que Spieker analiza.

El crítico alemán interviene en tales predios post-arqueológicos y postarchivísticos para indicar que el elemento fundamental de su teoría del archivo yace en las articulaciones, a veces intraducibles, de los aparatos psíquicos ya no exactamente freudianos: artefactos digitales, artilugios tecnológicos y conceptuales que producen el efecto del archivo.

Si en ese contexto se me pidiera una caracterización muy esquemática de la noción de archivo de Sven Spieker, diría, con base en una lectura acuciosa de su libro, que está compuesta de los siguientes elementos y referencias esenciales:

1. El aparato psíquico de Freud y el inconsciente traumático en donde operan las búsquedas (anti) archivísticas de Duchamp y Breton. 
2. La demasculinización del sentido arqueológico o el adelgazamiento del código 'originario' por parte de los experimentos de Duchamp.

3. El archivo del olvido, del shock, del éxtasis y del delirium (la data del inconsciente) y el azar objetivo del Primer Surrealismo.

4. El delgado orden burocrático: la tríada oficina, registro y archivo en el surrealismo de Breton y Artaud, en contraste con la estandarización de la que es objeto por parte de la vida tecnologizada de una era neocartesiana que propone Le Corbusier.

5. El museo viviente, el museo de cosas vivientes, museo archivo, o sea, la incorporación del archivo en el museo.

6. El perspectivismo perceptual, la oscilación del visitante, el agente activo o el cuerpo en el museo y la galería.

7. El mito: el monumento versus el archivo de significantes compuestos por la naturaleza móvil de la base de datos y la naturaleza dispersa o entrópica de la fotografía.

8. Los diferentes tipos de punctum desde los que se articula la pulsión archivística del fotógrafo-artista. Uno hogareño, emotivo y subjetivo (Barthes), el otro distante, objetivo y socioeconómico (Kracauer).

9. El centro del vacío sociológico que indica Kracauer: un espacio de la (no) figuración que se labra a partir de significantes específicos, relativos a la experiencia traumática de la historia.

10. El archivo como operación mental reflexiva, obsesionada con la búsqueda de vínculos y relaciones. Se alude a la subjetividad deseante y productora de interpretaciones críticas del montaje vanguardista, y a la importancia vital que en el montaje tienen los significados que emergen del shock.

11. El vacío de los archivos y el juego conceptual en los museos y espacios de tensión estética, y la conformación que de allí se origina hacia el efecto del archivo.

\section{Principio de procedencia en el a priori histórico de Sven Spieker}

Ahora bien, en el presente ensayo falta todavía el análisis de un elemento esencial: el archivo del principio de procedencia tan caro según Spieker a la modernidad; asunto al que le dediqué, en gran medida, la primera parte de este extenso comentario, con miras a una cierta traducción y resumen de El gran archivo, y que constituye uno de los temas mediante los que Spieker organiza argumentalmente su libro.

En todo caso, la fascinación de Spieker por la historia que él mismo escribe del principio de procedencia, prevalece; quizá la misma fascinación 
que nos produce la búsqueda secreta, y una cierta metafísica materialista. ${ }^{4} \mathrm{El}$ encantamiento parecía estar en cómo, durante este periodo, la inquietud era el Otro lugar: eso siniestro hacia donde iba el viaje vigilante del arqueólogo que reconstruiría el tiempo orgánico al evento perdido. El viaje y la medición, la instrumentalidad imantada del principio arqueológico. De hecho, El gran archivo nos alimenta con una serie de instrumentos científicos, dedicándole más de un capítulo al aparato psíquico de Freud; en palabras de Spieker, el artilugio más ingenioso de una cierta modernidad. Y con Freud pasa algo que, aunque discreto, representa en mi lectura una fina hebra del argumento del libro. No se trata de un asunto que se manifieste en el contraste que Spieker trabaja a lo largo de su disertación, que oscila entre 1) este archivo plenamente construido en el Archivo Estatal Privado de Berlín en 1881, de un lado, y 2) la pulsión (anti) archivística que nace a principios de la década de 1920 como resultado de un malestar cultural expresado por el archivo anémico de Duchamp, del otro. En cambio, este aspecto se manifiesta con gran sutileza como aquello que del asunto de la procedencia continúa activo, y me aventuro a denominarlo el a priori histórico de Spieker. Este aparato psíquico que Freud dibuja logra atravesar la rigidez masculina del espíritu científico decimonónico, profundamente arriesgado sin embargo, para derivar en regiones inconscientes en donde incluso la escritura desfallece. Con Freud se abre una zona desconocida; de esas que los arqueólogos perseguían, pero ahora en los dominios más salvajes e indómitos de la naturaleza psíquica. Lo que Freud apuntala sigue siendo una exterioridad del archivo, un afuera, pero su existencia psicológica es inaprensible. Solo las inferencias, los diferimientos, las operaciones analíticas y cognoscentes ambiguas pueden acceder a una sustancia que no se detiene firme, que fluctúa, desaparece y se archiva en el silencio; en el trauma y el olvido.

Para terminar, creo importante retomar las diferencias que Spieker encuentra entre 1) el siglo XX y 2) el principio de procedencia del siglo XIX. En un resumen que refleja sobre todo los tres últimos capítulos, vale la pena resaltar esquemáticamente lo siguiente:

1. A partir de las innovaciones del Constructivismo Soviético en el diseño de las salas y de la reflexión del museo como archivo, se desecha la contemplación del archivo en calidad de "un inmóvil depósito

4 Obsérvese la palabra metafísica en la Introducción del libro: cuando Spieker advierte cómo el artista estadounidense Morris "baipasea la metafísica archivística del siglo XIX (el archivo transcribiendo el murmullo del tiempo en sí mismo)" (Id. 13). 
de cosas": "No más la acumulación de objetos como horizonte del archivo" (Id. 112).

2. A partir de la nueva conceptualización de la visión, tiene lugar "un cambio en los parámetros de ver": el punto de vista del museoarchivo "no estará más basado en la autonomía de un punto de vista correcto (Ranke)" (Id. 109).

3. "Cambia el entendimiento newtoniano del espacio como un recipiente homogéneo para objetos [dirigido] hacia un proceso de diferenciación continua" (Ibid.), la arquitectura ya no es la base, sino el espectador y su actuación. El museo es un archivo dinámico de puntos de vista (Id. 122).

4. "Se desmantela la oposición [que hay] entre el archivo y la mirada" (Id. 114); entre el contenido y su apreciación visual. No se impone el fondo neutral del archivo que definió el siglo XIX para salvaguardar sus esfuerzos. Prevalece ahora la inmediatez de la mirada, que toca y habla directamente.

5. La imagen no precede su propio archivamiento.

6. Al archivo decimonónico, que fue una narrativa del movimiento en donde se representó la ilusión de continuidad y flujo, se le impone un archivo cuya escritura interrumpida va sujeta a momentos discretos y diferenciales: "se archiva la huella impermanente del espectador" (Id. 122).

7. Con herramientas como la base de datos, que permite una reagrupación modular, diversa y flexible - por el uso de fotografías-, queda puesta en tela de juicio la idea del archivo del siglo XIX, que correspondía con un orden original que el archivista adoptaba y preservaba.

8. Mientras que monumentos como el de Aleksandr Rodchenko a Lenin, que fue fundado en un resurgimiento del principio de procedencia que tuvo lugar en la época soviética de 1920, señalan un significante masculino (Lenin en este caso), "las bases de datos como la de Feldmann dramatizan una crisis de la archivación" (Id. 139), ya que, según la propia explicación del artista, los supuestos que la conforman no "pueden ser verificados con ningún grado de precisión" (Ibid.).

9. Tal como la asumió el espíritu científico del siglo XIX y su aspiración documental, la crisis del foto-archivo que encarna la obra de un artista como Feldmann pone en tela de juicio la visión de la fotografía como una tecnología y una práctica social capaz de una referencialidad veraz y una autenticidad histórica. 
10. Sin embargo, hay que señalar que la crítica de Feldmann ataca en el mismo grado al montaje y a la estética del shock. Spieker había observado en el montaje la primera gran reacción en contra del archivo del principio de procedencia, llamándolo arte del anti-archivo. Ahora, a diferencia del montaje, el conjunto de significantes no se articula produciendo significados solo a través de la yuxtaposición de sus elementos individuales y del shock como reacción lectora del espectador. En la apuesta de Feldmann, lo que importa es "el deseo subjetivo de interpretar, [de] establecer significados y relaciones causa y efecto", "lo que no puede ser detenido ni siquiera cuando esos vínculos no pueden ser confiablemente verificados" (Id. 140).

11. Así, en la lectura de Feldmann "el artista nos fuerza a aceptar el hecho de que las palabras e imágenes no concuerdan entre ellas, que las imágenes no muestran lo que las palabras prometen y viceversa" (Ibid.).

12. Finalmente, puede indicarse que, en oposición al sentido orgánico y único de la búsqueda arqueológica que se centra en la idealización de la procedencia de ese evento real (material) encubierto por el paso de la historia, y depositario del tiempo original perdido — tal la búsqueda de Troya-, emerge el efecto del archivo en el arte de creadores como Susan Hiller, entre la organización y la entropía: una dispersión radical, oscilación persistente entre diferentes marcos de referencias: histórico/mítico; factual/ficcional; subjetivo/científico; ordenado/caótico (Id. 183).

\section{Obras citadas}

Derrida,Jacques. Mal de archivo. Una impresión freudiana (1994). Trad. Paco Vidarte.

Nápoles: Edición digital de Derrida en castellano, 1994. Web. 15 de octubre de 2016.

Foster, Hal. "An Archival Impulse". October 110 (Autumn 2004): 3-22. Impreso.

Foucault, Michel. La arqueología del saber. Trad. Aurelio

Garzón. México: Siglo XXI, 1999. Impreso.

Rancière,Jacques. "Las paradojas del arte político". El espectador emancipado.

Trad. Ariel Dilon. Buenos Aires: Manantial, 2011. 53-86. Impreso.

Sekula, Allan. "The Body and the Archive". October 39 (Winter 1986): 3-64. Impreso.

Spieker, Sven. The Big Archive: Art from Bureaucracy. Cambridge: The MIT Press, 2008. Impreso. 